\title{
Abdominal alterations in disseminated paracoccidioidomycosis: computed tomography findings*
}

\author{
Alterações abdominais da paracoccidioidomicose disseminada: achados por tomografia \\ computadorizada
}

\section{Marli Batista Fernandes Vermelho ${ }^{1}$, Ademir Silva Correia ${ }^{1}$, Tânia Cibele de Almeida Michailowsky ${ }^{1}$, Elizete Kazumi Kuniyoshi Suzart ${ }^{1}$, Aline Santos Ibanês ${ }^{2}$, Lanamar Aparecida Almeida ${ }^{3}$, Zarifa Khoury ${ }^{4}$, Mário Flores Barba $^{5}$}

Vermelho MBF, Correia AS, Michailowsky TCA, Suzart EKK, Ibanês AS, Almeida LA, Khoury Z, Barba MF. Abdominal alterations in disseminated paracoccidioidomycosis: computed tomography findings. Radiol Bras. $2015 \mathrm{Mar} / \mathrm{Abr} ; 48(2): 81-85$.

Abstract Objective: To evaluate the incidence and spectrum of abdominal computed tomography imaging findings in patients with paracoccidioidomycosis.

Materials and Methods: Retrospective analysis of abdominal computed tomography images of 26 patients with disseminated paracoccidioidomycosis.

Results: Abnormal abdominal tomographic findings were observed in 18 patients (69.2\%), while no significant finding was observed in the other 8 (30.8\%) patients.

Conclusion: Computed tomography has demonstrated to play a relevant role in the screening and detection of abdominal abnormalities in patients with disseminated paracoccidioidomycosis.

Keywords: Paracoccidioidomycosis; Disseminated paracoccidioidomycosis; Abdominal computed tomography.

Resu mo Objetivo: Avaliar a frequência e variedade de achados de imagem por exames de tomografia computadorizada de abdome em indivíduos com paracoccidioidomicose disseminada.

Materiais e Métodos: Estudo retrospectivo dos exames de tomografia computadorizada de abdome de 26 pacientes com paracoccidioidomicose disseminada.

Resultados: Foram encontradas alterações tomográficas abdominais em 18 pacientes $(69,2 \%)$ dos casos analisados e 8 pacientes $(30,8 \%)$ apresentaram exames normais.

Conclusão: A tomografia computadorizada de abdome mostrou grande importância no rastreamento e identificação de alterações abdominais nos pacientes com paracoccidioidomicose disseminada.

Unitermos: Paracoccidioidomicose; Paracoccidioidomicose disseminada; Tomografia computadorizada de abdome.

\section{INTRODUCTION}

Paracoccidioidomycosis (PCM), Lutz disease or South American blastomycosis is a systemic fungal infection caused by the primary pathogenic, thermally dimorphic, saprophytic fungus Paracoccidioides brasiliensis discovered in $1908^{(1-6)}$. Brazil.

* Study developed at Instituto de Infectologia Emílio Ribas (IIER), São Paulo, SP,

1. Titular Members of Colégio Brasileiro de Radiologia e Diagnóstico por Imagem (CBR), MDs, Radiologists, Unit of Computed Tomography - Instituto de Infectologia Emílio Ribas (IIER), São Paulo, SP, Brazil.

2. MD, Resident in Infectology at Instituto de Infectologia Emílio Ribas (IIER), São Paulo, SP, Brazil.

3. Master, Technical Director, Division of Diagnostic and Therapeutic Support Instituto de Infectologia Emílio Ribas (IIER), São Paulo, SP, Brazil.

4. $\mathrm{PhD}, \mathrm{MD}$, Infectologist, Division of Deep Mycoses - Instituto de Infectologia Emílio Ribas (IIER), São Paulo, SP, Brazil.

5. Post-doctoral Scholar, MD, Radiologist at Unit of Computed Tomography Instituto de Infectologia Emílio Ribas (IIER), São Paulo, SP, Brazil.

Mailing Address: Dra. Marli Batista Fernandes Vermelho. Divisão de Apoio Diag nóstico e Terapêutico - Instituto de Infectologia Emílio Ribas. Avenida Doutor Arnaldo, 165, Cerqueira César. São Paulo, SP, Brazil, 01246-900. E-mail: marlivermelho@ globo.com.

Received December 13, 2013. Accepted after revision August 20, 2014.
In culture medium at room temperature, as well as in nature, this fungus is found in the form of septate hyphae or mycelia whose reproduction is asexual, generating chlamydospores. In cultures at $37^{\circ} \mathrm{C}$ or in infected tissues this fungus is found in the form of yeast which reproduces by asexual budding and that is easily identifiable at optical microscope si-3,6-8) $^{(1-2}$

In the American continent, this fungus may be found from the Southern region of the United States of America to Argentina ${ }^{(9)}$. Approximately $80 \%$ of reported cases of paracoccidioidomycosis are concentrated in Brazil, where São Paulo is the state with the highest prevalence, followed by Rio de Janeiro, Minas Gerais and Paraná, besides the Southern and Midwest regions. This is the most frequent endemic mycosis in the Central and South Americas ${ }^{(2,6,7,10)}$. In Brazil, the disease represents a relevant public health problem. Studies demonstrate that about $75 \%$ of the adult population was exposed to the fungus, but only $2 \%$ will develop the disease ${ }^{(2)}$.

The affected individuals require long-term assistance and follow-up and, considering that they are in the most produc- 
tive phase of their lives, this disease implies significant social-economic impact ${ }^{(5,6)}$. The male population is most affected, particularly in the age range between 30 and 60 years (13 men : 1 woman $)^{(5,6,9)}$. In the pre-adolescent population, the male-to-female ratio is $1: 1^{(9)}$.

The classification adopted by the Brazilian Paracoccidioidomycosis Consensus includes the following clinical presentations ${ }^{(5)}$ :

- PCM infection;

- PCM disease: a) acute/subacute form; b) chronic form - either unifocal or multifocal; c) sequelar form.

PCM infection is either asymptomatic or oligosymptomatic. After the infection, the progression to clinically apparent disease depends on the inhaled fungus virulence, besides their amount and presence of immune defense mechanisms of the infected individual ${ }^{(5-7,11)}$.

PCM disease may present as follows:

- Acute/subacute form: responsible for $3 \%$ to $5 \%$ of cases, with predominance in children and adolescents. It is characterized by a rapid evolution, and the patient seeks medical assistance between 4 and 12 weeks, presenting with lymph node enlargement, hepatosplenomegaly, digestive disorders (diarrhea, intestinal constipation, ascites, malabsorption syndrome, etc.), osteoarticular involvement and skin lesions $^{(5,12)}$.

- Chronic form: $90 \%$ of cases, with predominance in male adult individuals. This is a slow-growing condition and it may take years until the diagnosis is made. Pulmonary manifestations are frequently observed. There are two subtypes, namely, unifocal, as the condition is limited to a single organ; and multifocal, as it concurrently affects more than one organ ${ }^{(5-7,11)}$. PCM can spread through the body in several ways, namely, hematogenous, lymphatic, canalicular dissemination, and by contiguity ${ }^{(4,6)}$.

- Sequelar form: cicatricial manifestations following the disease treatment ${ }^{(5,6)}$.

Considering that some of the possible abdominal PCM manifestations may not be characterized by physical examination, an imaging evaluation including computed tomography $(\mathrm{CT})$ is required for a better definition of the affected organs.

\section{MATERIALS AND METHODS}

Retrospective study developed at Instituto de Infectologia Emílio Ribas (IIER) in São Paulo, SP, Brazil, with 26 patients with confirmed diagnosis of disseminated PCM, among individuals who underwent medical consultation and were referred for abdominal CT scan over an estimated 24month period starting on June 1st, 2010.

The present study was compliant with a term of data reliability according to the guidelines of the Committee for Ethics in Research of the authors' institution.

The scans were performed in an 8-channel multislice Light Speed CT apparatus (GE Healthcare; Wisconsin, USA), with images acquisition according to the protocols established by the radiology service at the authors' institution. The abdominal CT scans included an initial non-iodinated contrast-enhanced phase, and arterial, portal and equilibrium phases after oral and intravenous administration of iodinated contrast medium Optiray ${ }^{\mathrm{TM}} 320$ (Mallinckrodt do Brasil; São Paulo, Brazil), documented on appropriated windows and levels for abdominal organs assessment, with standard slice thickness of $7.5 \mathrm{~mm}$ at $7.5 \mathrm{~mm}$ intervals, and segments reformatting in the coronal and sagittal planes, as necessary.

The present study sample included both inpatients and outpatients of the authors' institution, regardless their complaints about abdominal symptoms, comprising 20 male and 6 female patients with minimum age of 18 and no maximum age limit, including HIV-positive individuals, and excluding pregnant women. The included patients were indistinctively under either previous or current use of medication specific for treatment of this deep mycosis.

Typical findings of abdominal PCM, such as organomegaly, lymph node enlargement, focal parenchymal lesions, gastrointestinal involvement, biliary tract or vena cava compression and ascites ${ }^{(5,6)}$ were demonstrated by CT.

\section{RESULTS}

Tomographic findings of abdominal abnormalities were observed in 18 patients, corresponding to $69.2 \%$ of the cases analyzed in the present series. For the remaining 8 patients (30.8\%), the CT images were normal.

The CT findings were classified into negative results, corresponding to presence of alterations; and identifiable findings, the latter subclassified into seven categories as shown on Table 1.

Hepatomegaly was defined as longitudinal axis of the right liver lobe $>15.5 \mathrm{~cm}$ at the hepatic midline ${ }^{(13)}$, or 16.0 $\mathrm{cm}$ at the midclavicular line $\mathrm{e}^{(14)}$, and splenomegaly as increased, i.e. $\geq 480^{(15)}$. In the present series, increased dimensions of these organs were a common finding, with predominance of hepatomegaly, detected in $11(42.3 \%)$ of the

Table 1-Types of alterations revealed at CT in 26 PCM patients.

\begin{tabular}{lcc}
\hline CT findings & No. of patients & Percentage \\
\hline Hepatomegaly & 11 & $42.3 \%$ \\
Suprarenal gland alterations & 7 & $26.9 \%$ \\
- increased dimensions & 3 & $11.5 \%$ \\
- nodular lesions & 2 & $7.7 \%$ \\
- calcifications & 4 & $15.4 \%$ \\
Splenomegaly & 6 & $23.1 \%$ \\
Abdominal lymph node enlargement & 3 & $11.5 \%$ \\
- intracavitary & 3 & $11.5 \%$ \\
- retroperitoneal & 3 & $11.5 \%$ \\
Calcified lymph nodes & 3 & $11.5 \%$ \\
Ascites & 2 & $7.7 \%$ \\
Focal splenic lesions & 2 & $7.7 \%$ \\
- microabscesses & 1 & $3.8 \%$ \\
- calcifications & 1 & $3.8 \%$ \\
\hline
\end{tabular}


patients. In all of the cases, hepatomegaly and splenomegaly were reported as mild to moderate.

Splenomegaly was detected in $6(23.1 \%)$ of the CT images analyzed in the present study, and in most cases was considered mild according to the established criteria, with homogeneous density. A small percentage of these patients (7.7\%) presented focal splenic lesions represented by small peripheral calcifications in one case (3.8\%), and by small, sparse, non-contrast-enhanced, hypodense lesions identified in one of the patients $(3.8 \%)$. The same patient who presented small splenic calcifications also presented minute peripheral hepatic calcifications and had co-infection by HIV virus, and the exact nature of such findings could not be established - whether secondary to a previous HIV-related opportunistic infection or by concomitant infection by the disseminated PCM.

Suprarenal glands alterations (Figures 1 and 2) were found in 7 out of the 28 cases $(26.9 \%)$, with a balanced distribution between increased gland dimensions $(11.5 \%)$ and

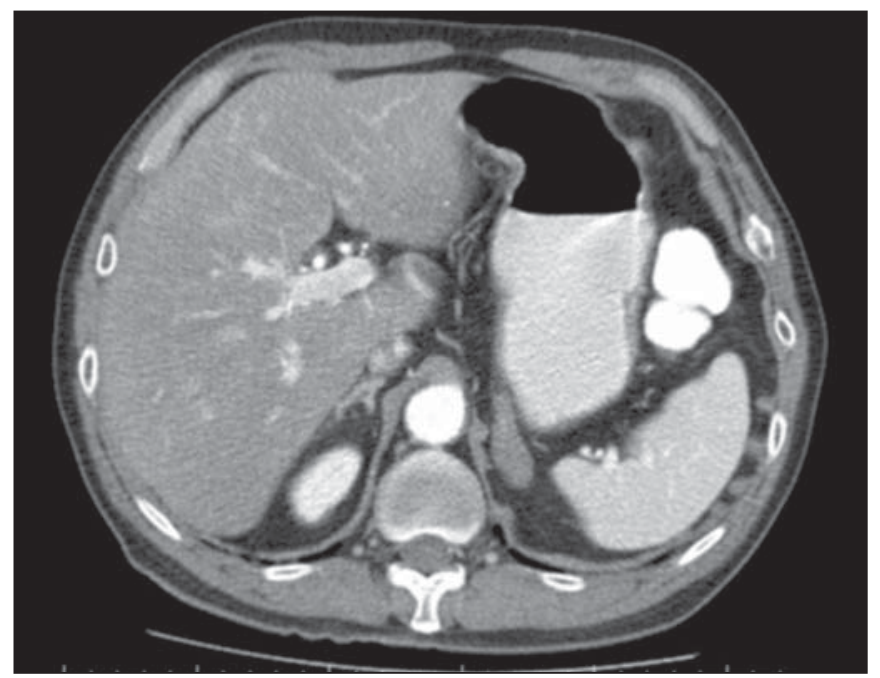

Figure 1. Abdominal CT, portal phase showing enlarged left suprarenal gland.

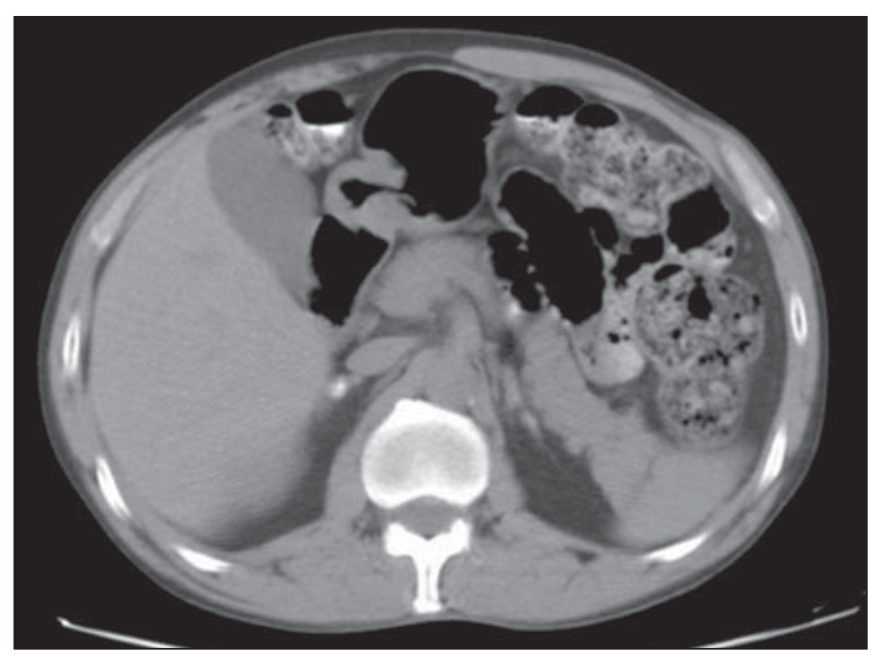

Figure 2. Non-contrast-enhanced abdominal CT identifying calcifications in suprarenal glands. presence of calcifications (15.4\%). A smaller percentage of patients presented solid nodular lesions $(7.7 \%)$, totalling 2 cases, one of them with the nodule density at the precontrast phase suggesting adenoma, and the other with a nodule with atypical contrast uptake. The maximum nodule size was 24 $\mathrm{mm}$. And the suprarenal calcifications varied between fine granular and focal gross calcifications.

Lymph node enlargement was the fourth most prevalent finding (11.5\%), with even distribution between intracavitary and retroperitoneal sites, and the same patients presented simultaneous involvement of different lymph node chains (Figure 3). Calcified Lymph nodes were found in three patients (11.5\%). In the described cases, enlarged lymph nodes do not exceed $30 \mathrm{~mm}$, and lymph nodes with hypodense Center were observed in one case. In general, nodal calcifications presented with a gross aspect. Figure 3 illustrates a case of abdominal CT at portal phase revealing lymph node conglomerate with hypodense areas suggesting necrosis or liquefaction in the peripancreatic region in association with splenomegaly.

Ascites was found in two cases $(7.7 \%)$, and was classified as being of small volume.

Other findings included one hypervascular liver nodule (interpreted as hemangioma), liver cysts and focal hepatic calcifications considered as residual.

Considering the frequency of tomographic alterations according to the disease clinical presentations, 10 cases (38.5\%) were classified as disseminated acute/subacute disease, and 9 out of such patients $(90 \%)$ had positive findings, and one (10\%) had no detectable alteration. Other 16 individuals in the present series $(61.5 \%)$ had chronic disseminated disease, and tomographic findings were observed in 9 of such patients $(56.2 \%)$, with no alteration in the other 7 cases $(43.8 \%)$.

As regards types of alterations in terms of clinical presentation observed in the patients with disseminated acute/ subacute disease, 9 (34.6\%) had hepatomegaly, 3 (11.5\%)

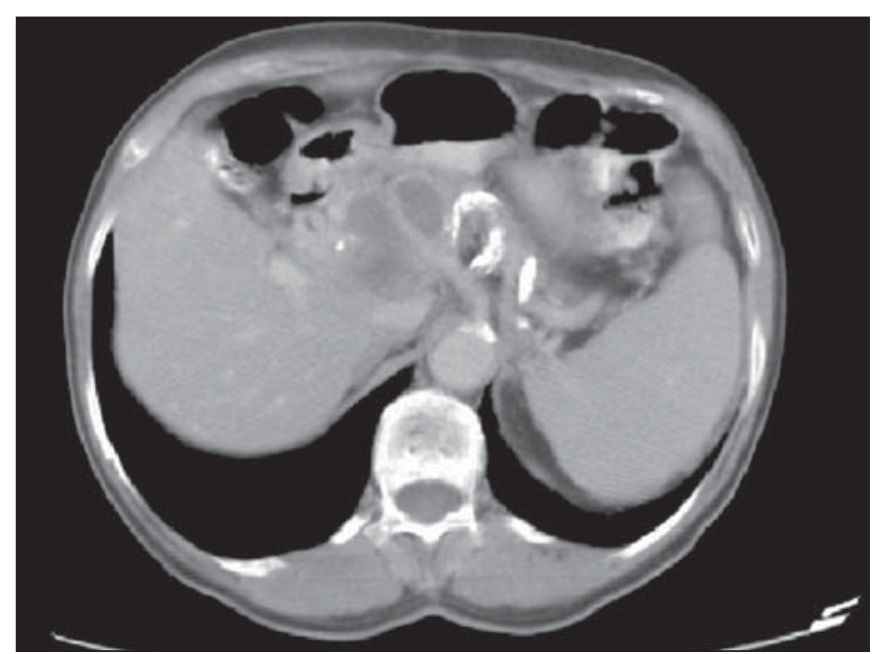

Figure 3. Abdominal CT, portal phase revealing lymph node conglomerate with hyperdense areas suggestive of necrosis or liquefaction in the peripancreatic region associated with splenomegaly. 
had splenomegaly, $2(7.7 \%)$ presented calcified lymph nodes, $2(7.7 \%)$ had enlarged suprarenal glands, in one $(3.8 \%)$ splenic microabscesses were identified, one $(3.8 \%)$ revealed signs of intracavitary lymph nodes enlargement, one $(3.8 \%)$ presented retroperitoneal lymph nodes enlargement, one $(3.8 \%)$ had splenic calcifications, and in one $(3.8 \%)$ suprarenal calcifications were described.

In the cases diagnosed with disseminated chronic disease the distribution of findings was the following: in 3 cases (11.5\%), suprarenal calcifications; in $2(7.7 \%)$, intracavitary lymph nodes enlargement; in $2(7.7 \%)$, retroperitoneal lymph nodes enlargement; in $2(7.7 \%)$, suprarenal nodule; in 2 $(7.7 \%)$, splenomegaly; in $2(7.7 \%)$, ascites; in one $(3.8 \%)$, suprarenal glands enlargement; in one $(3.8 \%)$, calcified lymph nodes; and in one case $(3.8 \%)$, hepatomegaly.

\section{DISCUSSION}

Abdominal involvement in PCM disease may be either oligo- or asymptomatic, but it is hardly diagnosed at clinical examination, so its frequency is underestimated ${ }^{(12,16,17)}$.

In the present study, abdominal alterations were found in 18 patients $(69.2 \%)$, i.e., a significant number of cases. The authors could observe that, even with the current treatments and drugs, the finding of abdominal alterations was frequent, corroborating previous studies results ${ }^{(12,17)}$, and the finding of tomographic alterations was more frequent in the acute/subacute presentation, visualized in $90 \%$ of the cases, than in the chronic presentation, where imaging findings were observed in $56.2 \%$ of the patients, in agreement with the literature ${ }^{(12)}$.

Hepatosplenomegaly represented a significant percentage of the findings in the present series, and is more frequently found in the disseminated acute/subacute presentation of the disease than in the chronic presentation, in agreement with previous reports ${ }^{(5,11,12)}$.

The findings in suprarenal glands and lymph nodes reinforce the relevant involvement of these sites in the disseminated presentation of the disease, as described by other studies $^{(1,4,12,16)}$. The finding of suprarenal nodules $(7.7 \%)$ was not considered to be specific of the disease according to the adopted tomographic criteria. The most typical form of suprarenal involvement is described as heterogeneously contrast-enhanced mass with a hypodense central area corresponding to caseous necrosis ${ }^{(15-17)}$. According to the literature, calcifications are present in about half of the cases of suprarenal involvement by $\mathrm{PCM}^{(15,16)}$, and gland atrophy is observed in the chronic stage of the disease ${ }^{(16)}$. In the present study, calcifications were found in $15.4 \%$ of the cases ? a lower prevalence than the one described for this disease. This was the most frequent finding in the chronic presentation of the disease. Bilateral suprarenal enlargement concomitant with radiographic findings of thoracic alterations suggesting PCM are highly indicative of the disease ${ }^{(15,16)}$, and this was observed in $11.5 \%$ of the cases in the present series, with a higher frequency in patients with acute/subacute disease.
The disseminated acute/subacute PCM presentation is characterized by the dissemination of the infection to the reticuloendothelial system, resulting in lymph nodes enlargement and splenomegaly ${ }^{(11)}$. A previous study described a significant percentage of findings of lymph nodes enlargement in patients with $\mathrm{PCM}^{(12)}$, a percentage superior to half of the cases in that series, attributable to the preferential $P$. brasiliensis lymphatic dissemination ${ }^{(4,16)}$. In the present study, such percentage was lower $(11.5 \%)$, a fact that may result from a selection bias, since most of the patients $(61.5 \%)$ had chronic disease. In spite of this fact, the authors observed a slightly higher frequency in the characterization of lymph nodes enlargement in cases of chronic disease (12.5\%) than in acute/subacute disease (10.0\%).

Ascites was one of the less frequent tomographic findings $(7.7 \%)$, and was also described in cases of disseminated PCM by previous studies ${ }^{(5,8)}$, differently from the present series where it was found only in patients with chronic disease.

Intra- and extra-hepatic biliary tract dilatation was reported as a frequent finding in a previous study ${ }^{(12)}$, but in the present series this finding was not identified, probably due to the smaller proportion of patients with acute/subacute disease. Additionally, the described lymph nodes enlargement did not exceed $30 \mathrm{~mm}$, with lower risk of secondary biliary tract compression.

\section{CONCLUSION}

The present series, although limited, demonstrates the relevance of tomographic findings in the staging of the abdominal involvement in PCM, considering that $69.2 \%$ of the patients under previous and current treatment for this systemic mycosis presented alterations at abdominal CT - a high frequency in agreement with data in the literature. The authors highlight the findings of hepatosplenomegaly, lymph nodes enlargement and suprarenal glands alterations.

\section{Acknowledgements}

The authors thank the Radiologist Rodrigo Delfino Nascimento for his collaboration reviewing the present text.

\section{REFERENCES}

1. Restrepo A, Tobón AM, Agudelo CA. Paracoccidioidomycosis. In: Hospenthal DR, Rinaldi MG, editors. Diagnosis and treatment of human mycoses. 1st ed. Totowa, NJ: Humana Press; 2008. p. 33142.

2. Travassos LR, Taborda CP, Colombo AL. Treatment options for paracoccidioidomycosis and new strategies investigated. Expert Rev Anti Infect Ther. 2008;6:251-62.

3. Carmo Junior J, Rodrigues JHL, Adad SJ, et al. Paracoccidioidomicose: formas abdominais abordadas cirurgicamente. Rev Med Minas Gerais. 1991;1:3-5.

4. Costa MAB, Carvalho TN, Araújo Júnior CR, et al. Manifestações extrapulmonares da paracoccidioidomicose. Radiol Bras. 2005;38: 45-52.

5. Shikanai-Yasuda MA, Telles Filho FQ, Mendes RP, et al. Consenso em paracoccidioidomicose. Rev Soc Bras Med Trop. 2006;39:297310 . 
6. Veronesi R, Focaccia R, Dietze R. Doenças infecciosas e parasitárias. $9^{a}$ ed. Rio de Janeiro, RJ: Guanabara Koogan; 2008.

7. Goldani LZ. Gastrointestinal paracoccidioidomycosis: an overview. J Clin Gastroenterol. 2011;45:87-91.

8. Fonseca LC, Mignone C. Paracoccidioidomicose do intestino delgado: aspectos anátomo-clínicos e radiológicos em 125 casos. Rev Hosp Clin Fac Med S Paulo. 1976;31:199-207.

9. Blotta MH, Mamoni RL, Oliveira SJ, et al. Endemic regions of paracoccidioidomycosis in Brazil: a clinical and epidemiologic study of 584 cases in the southeast region. Am J Trop Med Hyg. 1999 61:390-4.

10. Brummer E, Castaneda E, Restrepo A. Paracoccidioidomycosis: an update. Clin Microbiol Rev. 1993;6:89-117.

11. Franco M, Montenegro MR, Mendes RP, et al. Paracoccidioidomycosis: a recently proposed classification of its clinical forms. Rev Soc Bras Med Trop. 1987;20:129-32.

12. Martinez R, Bellucci AD, Fiorillo AM. A tomografia computado- rizada na avaliação do comprometimento abdominal na paracoccidioidomicose. Rev Soc Bras Med Trop. 1988;21:47-50.

13. Gosink BB, Leymaster CE. Ultrasonic determination of hepatomegaly. J Clin Ultrasound. 1981;9:37-44.

14. Kratzer W, Fritz V, Mason RA, et al. Factors affecting liver size: a sonographic survey of 2080 subjects. J Ultrasound Med. 2003;22 $1155-61$.

15. Goldman SM, Kenney PJ. The adrenal gtlands. In: Lee JKT, Sagel SS, Stanley RJ, et al., editors. Computed body tomography with MRI correlation. 4th ed. Philadelphia, PA: Lippincott Williams \& Wilkins; 2006. p. 1312-73.

16. Marsiglia I, Pinto J. Adrenal cortical insufficiency associated with paracoccidioidomycosis (South American blastomycosis). Report de four patients. J Clin Endocrinol Metab. 1966;26:1 109-15.

17. Silva AL, Giacomin RT, Silva BD. Paracoccidioidomicose ganglionar abdominal calcificada. Rev Soc Bras Med Trop. 1991;24:2535 . 